\title{
Points of orientation
}

In this issue, Rebecca McLaughlan, Michael Annear, and Alan Pert examine the potential for design to contribute to the wellbeing of people in early- and mid-stage dementia (pp. 104-105). They raise urgent questions about public and semi-public space in the city, acknowledging the consequences of rapidly ageing populations in numerous Western countries. Alongside clear signage, addressing the perplexing effects of crowds, the provision of spaces to pause, and multi-sensory stimulation, the authors illustrate how points of orientation in architecture and urban design remain important for dementia sufferers. Noting how inclusivity is often discussed in terms of 'universal design', they reflect on the value of design specificity for this particular community. They stress the potential for architects to emphasise aspects of orientation in their projects.

Also in this issue, François Blanciak recounts a student design project conducted at the University of Sydney that was centred on Tokyo's Yamanote Line - the railway loop connecting that city's primary railway stations - examining how its infrastructure produces centres and limits in the urban fabric (pp.161-170). Infrastructure both breaks and reconstitutes limits in the city, he reflects. Blanciak asserts that Architecture should be insubordinate towards infrastructure, and buildings should help reorientate the individual towards the collective. Tokyo and its (prospective) infrastructure also figure in Hyunjung Cho's historical account of Kenzō Tange's 1960 speculative plan for a linear city laid over the fabric of that city, its striking imagery appearing in Reyner Banham's famous 1976 book Megastructure: Urban Futures of the Recent Past (pp. 139-150). Tange's megastructure sought to provide both orientation and services, Cho illustrates, as 'a gigantic machine for circulation [...] a palpable image of the coming information society'. The idea of the megastructure has since been claimed as the inevitable urban form of Brutalism, just as - a generation before - Le Corbusier's Radiant City was portrayed as the inevitable urban form of early modernism. Liat Savin Ben Shoshan attributes the foundations of Brutalism to images of childhood constructed through film and photography in 1950s Britain, which, she argues, became points of orientation in the work of Alison and Peter Smithson (pp. 115-126).

Philip Steadman pays tribute to the research of Lionel March in his Obituary, which opens this issue (pp. 100-103). March brought a distinctive mathematical and scientific rigour to the study of buildings and cities, Steadman reminds us, and he was active in the foundation of Computer-Aided Design and the digital modelling of urban form. March's work became a point of intellectual orientation for numerous architects and scholars, and we are pleased to remember his contributions here. 